\title{
NARRAÇÃO DE HISTÓRIAS BILÍNGUES: ANÁLISE DO ESPETÁCULO TEATRAL NEXT STATION
}

\author{
RENATO IZIDIO DA COSTA* \\ PATRICIA M. F. COELHO ${ }^{* *}$
}

\begin{abstract}
RESUMO
O objetivo deste estudo é explorar o conceito da narração bilíngue - inglês e português - em contação de histórias, especificamente do espetáculo bilíngue Next Station, apresentando as etapas desde a criação até a execução. $\mathrm{O}$ arcabouço teórico que sustenta este trabalho são as pesquisas de Abramovich (1991), Stanislavski (1994) e Busatto (2003, 2006).A metodologia é descritiva, partindo do pressuposto de Gil (2008), que vê na pesquisa descritiva a exposição de resultados por meio de análises e observações. Os resultados alcançados evidenciam que, a partir da encenação, ocorre a internalização da língua estrangeira de forma lúdica, conforme proposto pelo espetáculo. Aspectos técnicos, cenografia e adereços contribuirão na facilitação, execução e no entendimento desse ato. Nesta pesquisa, tendo como foco a análise do espetáculo bilíngue Next Station, propomos os objetivos a saber: (i) verificar o processo de narrar histórias; (ii) compreender como é feita a narração bilíngue usando as línguas portuguesa e inglesa no espetáculo apresentado; (iii) descrever etapas da montagem do espetáculo Next Station; e (iv) perceber contribuições pedagógicas,
\end{abstract}

* É Mestrando em Educação na Universidade Metodista de São Paulo. Professor de Língua inglesa. E-mail:

** É Doutora em Comunicação e Semiótica pela Pontifícia Universidade Católica de São Paulo e professora titular no PPGE da Universidade Metodista de São Paulo. Foi orientadora da pesquisa para o artigo. E-mail: patriciafariascoelho@gmail.com 
artísticas e linguísticas que o projeto possa oferecer. O intuito é o de que ele seja escalonável-replicável.

Palavras-chave: Ensino bilíngue, Narração de histórias, Lúdico.

\title{
NARRATION OF BILINGUAL STORIES: ANALYSIS OF THE BILINGUAL SHOW NEXT STATION
}

\begin{abstract}
The aim of this study is to explore the concept of bilingual narration - English and Portuguese - in storytelling, specifically the bilingual show Next Station, presenting the steps from creation to execution. The theoretical framework that supports this work is the research by Abramovich (1991), Stanislavski (1994) and Busatto $(2003,2006)$. The methodology is descriptive, based on the assumptions of Gil (2008), who sees in descriptive research the exposition of results through analysis and observations. The results achieved show that, from the staging, there is the internalization of the foreign language in a playful way, as proposed by the show. Technical aspects, scenography and props will contribute to the facilitation, execution and understanding of this act. In this research, focusing on the analysis of the bilingual show Next Station, we propose the following objectives: (i) to verify the storytelling process; (ii) to understand how the bilingual narration is done using Portuguese and English in the presented performance; (iii) to describe steps in the assembly of the Next Station show; and (iv) to perceive pedagogical, artistic and linguistic contributions that the project can offer. The intention is that it be scalable-replicable.
\end{abstract}

Keyword: Bilingual teaching, Storytelling process, Playful.

No século XXI, período marcado por desafios fundamentados pela globalização e pelas novas tecnologias, abriu-se um campo de estudos profícuo para o bilinguismo, dada a necessi- 
dade cada vez mais forte em aprender uma outra língua, geralmente oferecida em franquias de escolas de idiomas. A partir desse marco histórico, inicia-se a institucionalização no ensino de idiomas.

Toda essa trajetória caracteriza-se como bilinguismo, conforme Siguán e Mackey (1986), ou seja, o ensino-aprendizagem simultâneo de duas línguas: em geral, uma língua nativa - isto é, a língua materna, ou língua nacional - e uma língua estrangeira - também chamada de língua alvo ou língua de cultura. Dessa forma, abordaremos aqui a língua inglesa, que assumiu seu papel no território brasileiro por volta de 1654 e se mantém até hoje.

$\mathrm{Na}$ contemporaneidade, é possível afirmar que "o inglês, hoje, é a língua mais usada no mundo dos negócios, e em alguns países, como Holanda, Suécia e Finlândia, seu domínio é praticamente universal" (BRASIL, 1998, p. 23).

Compreendemos a importância do inglês através do seu papel na sociedade. Um falante nativo da língua portuguesa habilitado em outro idioma pode se apoiar no termo bilíngue para mostrar-se como sendo aquele individuo "possuidor de duas línguas", tendo em vista que ser bilíngue tem sido um fator extremamente importante e de grande destaque. O mercado de trabalho, em meio à competitividade, tem exigido dos profissionais o conhecimento intermediário de uma segunda língua, com destaque para o inglês, de acordo com Oliveira (2008).

Assim, evidencia-se a língua inglesa como foco principal, dando destaque e nivelando os cargos profissionais. No Brasil, ser bilíngue é visto com um diferencial e um grau de habilidade maior em qualquer atividade, principalmente no campo globalizado e mercadológico. De acordo com as pesquisas de Bialystok (2008) e Carlson; Meltzoff (2008), os indivíduos bilíngues superam os monolíngues em uma variedade de tarefas cognitivas.

Importante entendermos aqui o conceito de indivíduo bilíngue, que, para a maioria das pessoas, é aquele que domina duas línguas, ou seja, dois códigos linguísticos. Como lembra Valdés 
apud Heye (2001), na visão popular, ser bilíngue é o mesmo que ser capaz de falar duas línguas perfeitamente. Opondo-se a essa visão, que inclui apenas os chamados "bilíngues perfeitos", Macnamara (1967) propõe que "um indivíduo bilíngue é alguém que possui competência mínima em uma das quatro habilidades linguísticas (falar, ouvir, ler e escrever) em uma língua diferente de sua língua nativa" (MACNAMARA, 1967 apud HARMERS; BLANC, 2000, p. 6).

Neste artigo, salientamos que o indivíduo bilíngue não faz parte do conceito de ensino bilíngue, uma vez que essa modalidade de ensino se refere ao processo do inglês, ou qualquer outro idioma estudado, ser apresentado e ensinado dentro da escola. Nesse âmbito, a diferença é que o professor ensina o idioma integrado às outras matérias, como artes, matemática, geografia e história, e, com isso, o inglês passa a ser o meio de instrução para desenvolver os outros conhecimentos, e não uma matéria em si. No modo habitual, não há uma análise sistemática, mas somente um olhar mecânico da gramática. $\mathrm{Na}$ educação bilíngue aprofundada-se, por sua vez, em ambas as línguas ao mesmo tempo e de maneira integrada. Marcelino (2009) afirma que, na escola bilíngue, por exemplo, a língua é o principal condutor no processo de ensino-aprendizagem.

Por meio desses apontamentos entre língua inglesa e o campo bilíngue, evidenciamos analisar a importância e as possibilidades da arte narrativa a partir da perspectiva de Busatto (2003) e Abramovich (1991) dentro desse cenário, estabelecendo um diálogo sobre como é feita a prática da contação de histórias utilizando uma segunda língua, nesse caso, a língua inglesa, diante da análise do espetáculo bilíngue Next Station, propondo uma reflexão direcionada ao processo de ensino-aprendizagem em futuras pesquisas para professores, contadores de histórias e profissionais da área.

Chamamos a atenção sobre o conceito de arte narrativa, narração e/ou contação de histórias, pois muitos contadores 
apresentam essas definições resultando em um mesmo significado. Busatto (2003, p. 9-10), por exemplo, afirma que contar histórias é uma arte rara, cuja matéria-prima é o imaterial, e que nos liga ao indizível, trazendo respostas às nossas inquietações, expressando e corporificando o simbólico, tornando-se a mais pura expressão do ser.

Na perspectiva de Villardi (2005), o ato de contar histórias faz-se necessário e importante, pois, além de divertir e estimular a imaginação, há outros objetivos em questão (como educar, instruir, conhecer melhor os interesses pessoais, desenvolver o raciocínio) tendo como aliada a otimização de conteúdos e elevando o interesse pelas aulas, além da compreensão em diversas situações.

Mais do que contar histórias, destacamos a importância da escuta, pois, como afirma Busatto (2003), o hábito de ouvir histórias desde cedo ajuda na formação de identidades. No momento da contação, estabelece-se uma relação de troca entre contador e ouvintes, o que faz com que toda a bagagem cultural e afetiva desses ouvintes se sobressaia, assim, levando-os a mostrar quem são. "Contar histórias é uma arte porque traz significações ao propor um diálogo entre as diferentes dimensões do ser" (BUSATTO, 2003, p. 10). Concluímos a escuta nesse âmbito como um fator essencial, pois o espetáculo analisado utilizará duas línguas na sua execução, o português e o inglês.

No pensamento de Fernandes (2008), é por meio da escuta que os primeiros contatos com um texto geralmente ocorrem oralmente durante a infância. Esse contato inicial, em muitos casos, dá-se na forma de contação de histórias (FERNANDES,2008). Abramovich (1991) nos diz que ouvir histórias ${ }^{1}$ representa um momento especial e encantador, capaz de seduzir, maravilhar, dar prazer e divertir. É ouvindo histórias que se pode sentir (também) emoções importantes, como a tristeza, a raiva, a

1 O presente artigo não tem como propósito investigar a fundo o ato de ouvir, e sim a perspectiva do contar. 
irritação, o bem-estar, o medo, a alegria, o pavor, a insegurança, a tranquilidade, vivendo profundamente tudo o que as narrativas provocam em quem ouve com toda amplitude, significância e verdade que cada uma delas faz (ou não) brotar, pois o ato de ouvir é sentir e enxergar com os olhos do imaginário (ABRAMOVICH, 1991).

No entanto, antes de tudo, é importante termos a convicção de que a prática da contação de histórias é considerada uma das atividades fundamentais para o desenvolvimento da criança e um grande incentivo para que ela se interesse pelo livro e pela leitura (FERNANDES,2008).

No contexto educacional brasileiro atual, verifica-se que muitos professores ainda não fazem uso da narração de histórias, desconhecendo o quanto ela pode contribuir para a formação do aluno.

Observamos também que o número de professores que são adeptos à utilização da contação de histórias como metodologia para introduzir/iniciar um conteúdo é relativamente baixo. Acreditamos que isso se manifesta devido ao fato de existirem profissionais que não conhecem a temática a fundo, concluindo previamente que o ato de contar histórias deva estar, no contexto estudado, à parte do processo de ensino-aprendizagem (SANTHIAGO, 2018, p.73).

Ainda sobre a importância do contar a história, Busatto (2003) afirma tratar-se de uma atitude multidimensional e, na forma da contação, pode-se atingir não somente o plano prático, mas também o nível do pensamento e, sobretudo, as dimensões do mítico-simbólico e do mistério. Assim,

[...] conto histórias para formar leitores, para fazer da diversidade cultural um fato, valorizar as etnias, manter a história viva, para se sentir vivo, para encantar e sensibilizar 
o ouvinte, para estimular o imaginário, articular o sensível, tocar o coração, alimentar o espírito, resgatar significados para nossa existência e reavivar o sagrado [...]" (BUSATTO, 2003, p.45-46).

Portanto, é a partir desses significados que propomos nesta pesquisa o caminho que será percorrido na narração de histórias dentro do universo bilíngue, a fim de construir uma análise sob a ótica do espetáculo bilíngue Next Station, a ser apresentado em escolas públicas e particulares da cidade de São Paulo. O projeto faz parte da criação do ator, contador de histórias e professor de línguas Renato Izídio. A investigação do espetáculo se dá desde a sua criação até o momento de estreia.

O arcabouço teórico sobre o ato de contar histórias utilizado nesta pesquisa destaca os estudos de Abramovich (1991), Busatto (2003) e Villardi (2005). No que tange ao bilinguismo, os estudos de Macnamara (1967), Marcelino (2009) e Baker (1998) serão abordados.

Nesta pesquisa, tendo como foco a análise do espetáculo bilíngue Next Station, propomos os seguintes objetivos para evidenciar os fatos: (i) verificar o processo de narrar histórias; (ii) compreender como é feita a narração bilíngue usando as línguas portuguesa e inglesa no espetáculo apresentado; (iii) descrever as etapas da montagem do espetáculo Next Station; (iv) perceber as contribuições pedagógicas, artísticas e linguísticas que o projeto pode oferecer.

A metodologia utilizada neste artigo é a empírica, partindo do pressuposto de Gil (2008), que vê na pesquisa descritiva a exposição de resultados por meio de análises e observações.

\section{A CRIAÇÃO DO ESPETÁCULO}

Diversas atividades foram lançadas visando o desenvolvimento de um olhar criativo na concepção do espetáculo. A elaboração de um projeto consiste em formar algo novo ou tornar 
diferente algo que já existe. Severo e Silva (2006) afirmam que o processo de criação nasce com a identificação de uma necessidade que estimula uma pessoa ou um grupo de pessoas a buscar uma forma de satisfazer essa necessidade. Logo, surge a fase de busca e criação de diversas alternativas novas e diferenciadas e, posteriormente, suas análises e implementações. A partir dessa definição, iniciamos o processo criativo e de investigação do espetáculo bilíngue Next Station.

Essa investigação resulta do desdobramento de uma pesquisa que inclui uma viagem ao continente africano, em 2018, em que foi feita uma experiência com aproximadamente 40 crianças moradoras da região de Cape Town, na África do Sul, no instituto educacional, propondo vários experimentos, inclusive usando a narrativa de histórias em inglês/português. Chegando ao Brasil, a mesma experiência foi executada utilizando a oposição português/ inglês. Assim, o espetáculo criado com essas duas línguas teve o intuito de estimular o universo linguístico da criança e construir uma aproximação com a língua visada. Nesse espetáculo, a criança percebe a necessidade de se comunicar com o personagem Zé Sucupira (possuidor de uma linguagem cheia de estereótipos, considerada coloquial) que, vivendo no Brasil, tenta dialogar utilizando um novo dialeto (inglês), visto e ouvido na English Land.

Assim, por meio das experiências artísticas, verificamos a importância da narrativa bilíngue como um valioso instrumento de aprendizagem e assimilação de uma língua, uma vez que, a partir de métodos cênicos, a interação com a língua poderá vir de forma fácil, no contato com outras pessoas, e de maneira natural, conforme a ideia de Schütz (2002).

Segundo Santos Gargallo (2010, p. 19), a aquisição é um processo inconsciente de internalização de um sistema linguístico por exposição natural à língua. Por outro lado, a aprendizagem ocorre como um processo consciente, no qual se internaliza um sistema linguístico e cultural mediante a reflexão sistemática e guiada de seus elementos. 
Portanto, dentro do eixo narrativo, fica claro que, por mais objetos e/ou recursos que estejam à disposição do narrador, o mais importante é saber como usar, decidindo assim momentos certos para inseri-los dentro de cada campo da história, seja na língua nativa, seja em qualquer outro idioma e segmento de linguagem. Narrar exige preparação, habilidade e execução.

A primeira etapa de criação do espetáculo foi desenvolvida em um processo de aproximadamente um mês, que teve por objetivos responder às questões iniciais: como o autor gostaria de formatar ${ }^{2}$ o espetáculo, ou qual seria o método de contar histórias em outra língua? Qual gênero? Infantil, adulto, livre etc.? Que público gostaria de atingir? Falantes da língua inglesa ou não falantes? E onde gostaria de apresentar esse projeto? Quais seriam as etapas a serem desenvolvidas?

Todavia, essas questões são partes fundamentais para o processo de construção de um espetáculo e/ou de qualquer atividade artística. Parte teórica adotada na criação do espetáculo está baseada em considerações, análises e vivências dentro e fora da sala de aula nas escolas privadas em que o contador e professor de línguas Renato Izídio tem passado.

A principal tarefa para iniciar essas ações seria o planejamento que, de acordo com Maximiano (2004), é a atividade previamente definida para se estabelecer um fim desejado e os meios pelos quais esse fim será alcançado. Trata-se essencialmente de um processo de tomada de decisões, caracterizado pela existência e colocação de alternativas. Kotler e Armstrong (2003) reforçam ainda que o planejamento faculta ao indivíduo ou à instituição o pensar sistematicamente acerca do que está acontecendo ou do que acontecerá. Idealizar um projeto artístico torna-se complexo quando não se sabe qual será o resultado, o que geralmente se dá somente após o processo de montagem e execução.

2 Na linguagem teatral, são usados alguns termos que teriam outro sentido na linguagem usual. Nesse sentido, a palavra formatar aqui tem o mesmo sentido de "conceber uma forma lógica ou estrutura". 
O segundo ponto importante nessa fase da construção do espetáculo seria o domínio de uma segunda língua (neste estudo, destacamos a língua inglesa). É possível afirmar na contemporaneidade que o inglês, hoje, é a língua mais usada no mundo dos negócios, e em alguns países, como Holanda, Suécia e Finlândia, seu domínio é praticamente universal nas universidades (BRASIL, 1998, p.23).Destaca-se aqui o domínio, tanto da parte do contador em conduzir o espetáculo por aproximadamente 50 minutos, fazendo o uso de duas línguas, como também a capacidade de compreensão do público, que objetivamos com níveis de entendimento e idades diferentes.

Desse modo, observar a contação de histórias no século

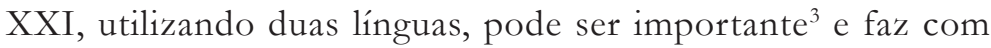
que se amplie o olhar para a criança contemporânea colocada em um ambiente em que falar inglês pode ser um diferencial, pois a língua inglesa é uma das mais requeridas nas instituições de ensino e, por consequência, nos postos de trabalho formal.

Portanto, para a criação do espetáculo fomos guiados por meio de um cronograma, colocando as seguintes etapas:

\begin{tabular}{|c|c|c|}
\hline Preparação & Montagem e ensaios & Estreia \\
\hline $\begin{array}{l}\text { duas a quatro } \\
\text { semanas (reu- } \\
\text { niões com artis- } \\
\text { tas de teatro) } \\
\text { Criação do } \\
\text { corpo e da ideia } \\
\text { do texto. }\end{array}$ & 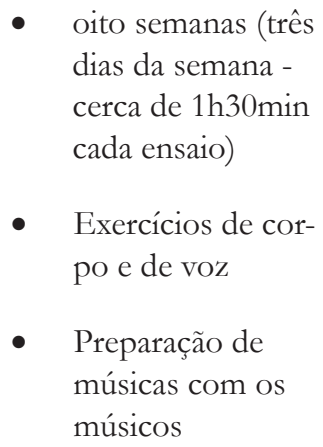 & $\begin{array}{l}\text { - Contato com } \\
\text { instituição } \\
\text { Pré-produção } \\
\text { com e-mails, } \\
\text { mapas técni- } \\
\text { cos, condições } \\
\text { do espaço e } \\
\text { quantidade de } \\
\text { público }\end{array}$ \\
\hline
\end{tabular}

Tabela 1. Cronograma de Preparação. Desenvolvida e criada pelo autor.

\footnotetext{
3 Devido à falta de pesquisadores acerca da temática, o autor deste artigo amplia o olhar sob a contação de histórias em outra língua a partir de suas próprias vivências.
} 
A ideia de montar o espetáculo Next Station surgiu a partir de conversas e de observações. Nas primeiras semanas de preparação, contactamos pessoas ligadas à arte, com experiência em criação de dramaturgias, ${ }^{4}$ de modo a ampliar o processo de ideias e de organização do texto a ser escrito. Logo em seguida, conversamos com nativos da língua inglesa, na tentativa de obter dialetos ou gírias para incrementar a escrita do espetáculo, oferecendo originalidade, materialidade e sentido ao processo.

Partindo desse cronograma, na criação do espetáculo, e por meio dos encontros com nativos da língua inglesa, objetivamos o uso de palavras e expressões em inglês que pudessem facilitar tanto o entendimento quanto o domínio da fala no corpo da dramaturgia. Dominar uma língua pode trazer um mundo mais amplo e com possibilidades, contribuindo assim na formação e no destaque em meio à sociedade moderna. De acordo com o linguista David Crystal apud Schütz (1998), “à medida que o inglês se torna o principal meio de comunicação entre as nações, é crucial garantirmos que seja ensinado com precisão e eficientemente".

Após as etapas de criação do texto, domínio da língua e a relação da comunicação entre ator e público, formatamos o espetáculo teatral na categoria bilíngue, visando oferecê-lo a um público com idades entre 1 e 10 anos. A intenção de o espetáculo ser destinado a crianças veio da observação de pais que buscam benefícios e serviços bilíngues, de acordo com a visão de Marcelino (2009), propagando a ideia de que o aluno inserido desde a infância nesse modelo terá grandes êxitos no segundo idioma. Por isso, foi pensado produzir um entretenimento para esse público, com o objetivo de suprir tal anseio de pais ou responsáveis na busca de serviços bilíngues. Como consequência, notamos a grande procura por escolas e/ou serviços bilíngues desde a infância, com o desejo de atender às exigências do mundo globalizado e das divulgações em massa.

4 Conversas com pessoas que têm domínio na área da escrita e que são especialistas na criação de roteiros. 
Portanto, o espetáculo se torna uma ferramenta de aprendizagem por meio da oralidade, dentro do contexto da contação de histórias bilíngues, assumindo que o resultado pode ser satisfatório. Abramovich (1997) considera a contação de histórias como portadora de significados para a prática pedagógica, não se restringindo ao seu papel de entendimento da linguagem, pois se preserva o caráter literário, a função de despertar a imaginação e sentimentos, assim como as possibilidades de transcender a palavra ${ }^{5}$, no caso em questão, a língua inglesa.

Nesse contexto, a ideia inicial de criação foi a de viabilizar a acessibilidade pela língua inglesa e proporcionar o entretenimento por meio do espetáculo aos falantes, desde o nível zero $^{6}$ até os considerados atuantes. Por esse caminho, o próprio projeto foi apontando alguns direcionamentos, tais como: a porcentagem de falantes que poderia alcançar, já que o nível de conhecimento do idioma inglês apresentado pelos brasileiros é considerado baixo, segundo os dados do British Council (2014) ${ }^{7}$; e os percursos a serem seguidos na apresentação, uma vez que cada indivíduo traz um domínio diferente em relação à língua. Assim, o ator buscou, por meio de preparação e ensaios, propostas que despertassem o desejo e a curiosidade do público em relação a cada palavra dita no espetáculo.

\section{A PREPARAÇÃO E O ATO DE NARRAR BILÍNGUE}

Antes de começar a me concentrar sobre um papel específico, antes de pensar na criação do círculo de atenção no qual tenho que fazer entrar estas ou aquelas "circunstâncias dadas" do papel, tenho primeiro que libertar a mim mesmo

\footnotetext{
5 Nesse momento, a proposta é criar o espetáculo usando essas duas línguas - português e inglês - com a finalidade de propor caminhos para almejar uma segunda língua e adquirir gosto por ela.

6 Falantes que nunca tiveram contato com a língua inglesa.

7 Dados disponíveis: https://www.britishcouncil.org.br/sites/default/files/ demandas_de_aprendizagempesquisacompleta.pdf. Acesso em: 26 jan. 2020.
}

118 Cadernos de Educação, v.20, n. 40, jan.-jun. 2021 
das diferentes crostas e capas de minha vida privada que carrego até o momento em que comecei o trabalho criativo (STANISLÁVSKI, 1994, p. 89).

Seguindo a ideia do cronograma organizado pelo autor para a construção do espetáculo, houve uma preparação - desde a concepção da escrita até chegar ao trabalho de aprimoramento do ator - por meio dos ensaios e da criação das músicas que compunham as cenas. $\mathrm{Na}$ construção do personagem e no trabalho do ator, averiguamos que "a caracterização externa explica e ilustra e, assim, transmite aos espectadores o traçado interior de seu papel” (STANISLAVSKI, 1970, p. 27). Verifica-se na sequência que quanto mais se utilizam elementos externos que ajudem o ator em sua caracterização, e que contribuam na construção da personagem por meio de pesquisas, sejam elas no modo prático ou teórico, mais o trabalho ficará ajustado. Nessa perspectiva, a compreensão se amplia em relação à maneira de se contar a história em outra língua, sendo necessária a construção do personagem de forma caracterizada, com figurinos, gestos, voz, e que vai ganhando vida durante as muitas fases em que o projeto vai sendo construído.

Observa-se que, além do trabalho do ator, há dificuldades ao se pensar a centralidade do espetáculo teatral: por exemplo, o questionamento sobre qual seria o percurso mais fácil para se chegar a um resultado consideravelmente satisfatório, tanto no campo da atuação quanto no de entendimento da segunda língua, considerando um público com idades entre 1 e 10 anos, e que tivessem conhecimentos, nivelamentos e domínios diferentes em relação à língua inglesa.

A partir dessas observações, depreendemos algumas inquietações que são vistas e repensadas. De que forma o autor/ator poderia verificar o processo de narração de histórias bilíngues? De que maneira o ator poderia fazer toda a trama sem os recursos ou efeitos da tradução? Como seria dado o processo de aquisição da segunda língua por meio de um espetáculo bilíngue? 
No momento da montagem, seguindo a ideia do cronograma apresentado, foi pensado sobre de que maneira o público poderia compreender as línguas trabalhadas durante o espetáculo, levantando hipóteses de que apenas o trabalho corporal não poderia sustentar a trama durante muito tempo. Desse modo, o autor do espetáculo decidiu incluir no planejamento o uso da metodologia CLIL (Content and Language Integrated Learning), ou seja, o conteúdo interligado ao ensino de uma determinada língua.

Na prática, o CLIL consiste em ministrar disciplinas e conteúdos diferentes por meio de uma língua estrangeira. Coyle (2015) vê nessa abordagem um facilitador de aprendizagem e de comunicação entre os alunos em outras possíveis linguagens, e ressalta ainda que, além do conteúdo, há uma abordagem mais complexa e profunda em relação às habilidades cognitivas e interculturais.

A face do espetáculo, desde a sua criação, estava voltada para essa teoria, pois, além de um entretenimento, seu objetivo era o de que os alunos, por meio da linguagem e da dramaturgia, adquirissem habilidades e conhecimentos da língua em exposição, sem que houvesse o mínimo recurso de tradução, e que, utilizando o CLIL e elementos lúdicos, pudessem sustentar todo o espetáculo. Todavia, no aspecto da narração, escolhemos fazer uso de personagens nativos em português, com elementos lúdicos ${ }^{8}$ que permitissem a chegada da segunda língua.

Entendemos o lúdico, segundo Oliveira (1985, p.74), como uma das atividades mais significativas diante do seu conteúdo pedagógico-social, pois o "o lúdico é [...] um recurso metodológico capaz de propiciar uma aprendizagem espontânea e natural. Estimula a crítica, a criatividade, a socialização”. Ao longo das

8 Durante a trama, um personagem encontra uma Magic Bag[mala mágica] que, por meio da ludicidade, possibilita ao nativo em língua portuguesa descobrir várias palavras da segunda língua, representando um recurso convidativo, tanto para o personagem quanto para as crianças que sentirão o desejo de ajudá-lo. 
cenas, adotamos como elementos lúdicos, músicas, manipulação de bonecos, interação com o público através da comicidade, utilizamos cartões (flashcards), além de muita leveza no emprego de cada palavra.

Aliando o lúdico ao campo da atuação, o ator ainda usou o corpo como elemento básico a fim de transportar movimentos comunicativos para o interlocutor, como gestos grandes, músicas corporais, mímicas e expressão facial.

Investigações de autores como Stanislávski ${ }^{9}$, na arte teatral, contemplam não apenas a busca artística, mas os meios pedagógicos, princípios e noções éticas que abrangem tanto o trabalho criativo quanto a conduta na vida.

Partindo desse pressuposto, percebemos que componentes da arte teatral, como voz, figurinos, composição do ator em cena, corpo aliado à oralidade, são alguns dos elementos que conduzem à capacidade de relação entre os seres da sociedade. Recursos visuais, por exemplo, podem constituir um meio de comunicação eficaz, estimulando a área sensorial e auxiliando o aprendizado da língua. Sendo assim, contaremos com os recursos da oralidade e da arte teatral para convencer, falar, transpor os desejos e até mesmo se comunicar em outra língua dentro do espetáculo Next Station.

O corpo, nesse aspecto, é um elemento primordial, na medida em que o ator se apoia nele para lançar "uma impressão espasmódica" (ARTAUD, 1987, p. 162). Para Artaud (1987), o ator é um atleta físico capaz de desenvolver uma "[...] muscu-

9 "Konstantin Sergeievich Stanislavski (né Alexeiev, russo: Константин Сергеевич Станиславский , 17 de janeiro de [OS 5 de janeiro] $1863-7$ de agosto de 1938) foi um praticante de teatro russo seminal. Foi reconhecido extensamente como um ator proeminente do caráter e as muitas produções que dirigiu lhe garantiram uma reputação como um dos diretores principais do teatro de sua geração. Sua fama principal e influência, no entanto, repousa sobre o seu 'sistema' de formação ator, preparação e técnica de ensaio”. Disponível em:http://arteeducacaoterapia.numin.org. br/konstantin-stanislavski/. Acesso em: 5 fev. 2020. 
latura afetiva que corresponda a localizações físicas dos sentimentos" (p. 162). Nessa perspectiva, o ouvinte poderia adquirir, além de um simples entretenimento, uma possível aquisição da segunda língua.

O significado de aquisição é ampliado à aprendizagem de uma segunda língua (L2), que ocorre de maneira similar à forma como uma criança aprende a sua primeira língua (L1), ou seja, por contato direto e de forma espontânea. Assim, a aprendizagem de uma L2 está relacionada ao estudo formal, que ocorre, geralmente, numa sala de aula, com um professor, com exercícios gramaticais e comunicativos que visem a fomentar o domínio e a conversação em L2 (MARTíN, 2004).

Dessa forma, para se obter uma vantagem significativa, de modo a adquirir o conhecimento da língua dentro desse projeto, a escolha foi trabalhar as narrativas por meio da ludicidade e de modo descontraído, enfatizando a língua inglesa.

Uma vez que elas são utilizadas extensivamente para a comunicação humana, tanto a compreensão como a produção oral e a escrita de narrações constituem parte fundamental do projeto.

Desse modo, nossa experiência é altamente influenciada pelo ato de compreender e produzir essas narrativas. Portanto, compreendemos que a contação de histórias será uma importante ferramenta na modalidade bilíngue.

\section{EXECUÇÃO DO ESPETÁCULO E SUAS CONTRIBUIÇÕES NAS PRÁTICAS PEDAGÓGICAS}

Conforme a ideia do cronograma criado pelo autor do projeto, a última etapa se desenvolveu com a execução do espetáculo, uma vez que, diante das etapas anteriores, foi percorrido um percurso de aproximadamente três meses até a data da estreia.

Toda a investigação realizou-se por meio das vivências em sala de aula e da experimentação da narrativa em diversos lugares, usando as duas línguas - inglês/português. Segundo Abramovich (1997), ao considerar a contação de histórias 
como portadora de significados para a prática pedagógica, seu papel não fica restrito somente ao entendimento da linguagem, pois se preserva seu caráter literário, sua função de despertar a imaginação e sentimentos, assim como suas possibilidades de transcender a palavra. Frisamos também os olhares dos ouvintes nos diferentes níveis de aprendizado na área da língua inglesa, sejam eles de um nível inicial, intermediário ou até mais elevado (aquele que consegue compreender o que está sendo dito).

A partir dos fatores que antecederam a criação do espetáculo, fizemos a pré-produção, na cidade de São Paulo, que consistiu na visitação de escolas e espaços nos quais desejaríamos nos apresentar. Visitamos inúmeras escolas bilíngues inglês/português a fim de oferece ruma relação próxima com a segunda língua. Outro fator visto nas escolas de grande porte em São Paulo foi o processo do storytelling ${ }^{10}$, termo definido pelos contadores de histórias que utilizam esse processo em suas narrativas totalmente em inglês. Assim, nessa etapa de produção, verificamos quais escolas poderiam receber o trabalho.

No entanto, na execução do espetáculo, é importante frisar que as escolas, bibliotecas e espaços culturais serviram de base para essa grande aventura, em especial as escolas bilíngues, pois nessas instituições percebemos uma proposta de metodologia inovadora em relação a outras escolas e centros de ensino de idiomas, justamente por se apoiarem nos fundamentos da educação bilíngue e nas práticas de storytelling. Porém, pensamos que o espetáculo também possa ser apresentado em escolas que possuem outras metodologias de ensino que não sejam bilíngues.

Os resultados serão obtidos a partir de uma pesquisa de análise de dados realizada pelo número de apresentações do espetáculo durante o tempo de circulação. Vale retificar que o projeto foi proposto pelo ator e diretor do espetáculo Renato Izídio, que também é professor de língua inglesa em escolas

10 O storytellingé usado em contação de histórias e pode ser visto em empresas de marketing e publicidade. 
privadas de São Paulo, e pelos músicos Mateus Motta (violão) e Mário Machado (clarinete).

No espetáculo Next Station, o autor dialoga o tempo todo com o público presente por meio das narrativas e das músicas com um contexto artístico e pedagógico, a fim de passar conhecimentos utilizando temas fundamentalmente presentes no enredo. O espetáculo conta a história do personagem Zé Sucupira que, ao tentar se deslocar para outros lugares, se depara com a English Land ${ }^{11}$, terra que tem como língua nativa o inglês. A partir dessa perspectiva, o personagem encontra vários caminhos para facilitar a comunicação.

Diante disso, constatamos que nas primeiras apresentações, o foco está no papel do narrador em conduzir o espetáculo, evidenciando também a qualidade do seu trabalho ao fazer o uso da narrativa em duas línguas, observando todo o tempo as maneiras e formas com que ele pode conduzir e dominar a fala, proferindo uma linguagem de maneira eficaz.

Especificamente sobre a linguagem, usaremos exemplos vistos principalmente no Brasil, mas que equivalem à língua inglesa, em que falar de maneira dita correta sempre foi uma das grandes preocupações dos brasileiros tornando esses mitos cada vez mais presentes. A partir disso o personagem do espetáculo, quebra essa preocupação e esses possíveis mitos, mostrando suas maneiras diferentes de falar, indo totalmente contra o circulo que envolve a gramática, evidenciando características do seu lugar de origem, carregado com muitos sotaques e arquétipos sem perder a essência de uma boa pronúncia.

Bagno (2007) afirma que esses mitos são transmitidos e perpetuados em nossa sociedade por meio de um mecanismo de círculo vicioso, que envolvem a gramática, o ensino tradicional e os livros didáticos: “[...] a gramática tradicional inspira a prática de ensino, que por sua vez provoca o surgimento da indústria do

11 English Land (Terra do Inglês), nome sugerido pelo escritor do espetáculo a fim de levar proximidade ao tema da história. 
livro didático, cujos autores - fechando o círculo - recorrem à gramática tradicional como fonte de concepções e teorias sobre a língua" (BAGNO, 2007, p. 73).

Apesar desses avanços, Bagno (2007, p. 74) reconhece que "é necessário um trabalho lento, contínuo e profundo de conscientização para que se comece a desmascarar os mecanismos perversos que compõem a mitologia do preconceito”. O autor também explica que ainda é mais difícil combater o preconceito que os falantes apresentam sobre si mesmos, acreditando que o português é uma língua difícil, ou que eles não sabem falar corretamente.

Portanto, podemos considerar que a contação de histórias pode ser uma ação facilitadora entre comunicação de linguagens, interferindo no desenvolvimento e nas habilidades oral, motora, linguística. Além disso, os elementos lúdicos têm sido grandes instrumentos nas experiências dos professores, em especial na vivência desse espetáculo. Para Santos (1999), o lúdico é uma maneira que o indivíduo tem de se expressar e de se integrar ao ambiente que o cerca.

De certa forma, consideramos, por esse viés, que o espetáculo contribui com as práticas pedagógicas, pois, por meio de atividades lúdicas, o indivíduo assimila valores, adquire conhecimentos em diversas áreas, desenvolve o comportamento e aprimora as habilidades motoras. Também aprende a assumir responsabilidades, torna-se sociável e mais crítico. Através do lúdico, o raciocínio é estimulado de forma prazerosa e a motivação em aprender é resgatada. Para Luckesi (2000, p. 97), a ludicidade "é representada por atividades que propiciam experiência de plenitude e envolvimento por inteiro, dentro de padrões flexíveis e saudáveis".

A intenção do professor, em um primeiro momento, quando entra em contato com a história, é dar importância à imaginação, pois, ouvindo, a criança pode entender o quão é bom imaginar e, a partir daí, não estará atenta apenas ao enredo da história, mas no cenário, nos gestos, na voz e no texto. Pen- 
sando no processo de ensino-aprendizagem, as crianças estarão inteiramente ligadas e focadas no que será transmitido. Assim, essas vivências se fixarão na memória do aluno, fazendo com que ele aprenda de uma maneira simples, clara e objetiva, por meio da contação de histórias.

Concluímos que o experimento em contar histórias em outras línguas, em especial a língua inglesa, além de ser prazeroso para o pesquisador/autor, é uma área extremamente inovadora, que pode ser vista como recurso pedagógico para usar em sala de aula, especialmente para ensinar a língua inglesa.

Destacamos também que toda a trajetória do espetáculo é marcada por incertezas, pois cada apresentação será diferente uma da outra, seja em decorrência do espaço, do público e da energia dos artistas. Podemos considerar nesse contexto artístico que cada apresentação se torna única, e o resultado pode ser variável.

\section{REFERÊNCIAS}

ABRAMOVICH, Fanny. Literatura infantil: gostosuras e bobices. 2. ed. São Paulo: Scipione, 1997.

ARTAUD, Antonin. O teatro e seu duplo. São Paulo: Editora Max Limonad, 1987.

BAKER, C.; PRYS JONES, S. Encyclopedia of Bilingualism and Bilingual Education - School or Education. University of Walles, Bangor: Multilingual Matters Ltd, 1998.

BAGNO, Marcos. Preconceito linguístico: o que é, como se faz. 49. ed. São Paulo: Loyola, 2007.

BRASIL. Ministério da Educação e do Desporto. Secretaria de Educação Fundamental. Referencial curricular nacional para a educação infantil. Brasília: MEC/SEF, 1998.

BIALYSTOK, E. Bilingualism: the good, the bad, and the indifferent. Bilingualism: Language and Cognition, v. 12, n. 1, p. 3-11, 2008. DOI: 10.1017/ S1366728908003477.

BUSATTO, Cléo. Contar e encantar: pequenos segredos da narrativa. Petrópolis: Vozes, 2003. 
BUSATTO, Cléo. A arte de contar histórias no século XXI: tradição e ciberespaço. Petrópolis: Vozes, 2006.

CARLSON, S. M.; MELTZOFF, A. N. (2008). Bilingual experience and executive functioning in young children. Developmental Science, v. 11, n. 2, p. 282-298, 2008. DOI: https://doi.org/10.1111/j.1467-7687.2008.00675.x.

COYLE, Do. Strengthening integrated learning: Towards a new era for pluriliteracies and intercultural learning. Latin American Journal of Content \& Language Integrated Learning, v. 8, n. 2, p. 84-103, 2015.

FERNANDES, Jaqueline.Contando histórias na brinquedoteca escolar: uma proposta de incentivo à leitura na educação infantil. 2008. Dissertação (Bacharelado em Biblioteconomia) - Faculdade de Comunicação e Biblioteconomia - Universidade Federal de Goiás, GO, 2008. Disponível em: https://repositorio.bc.ufg.br/bitstream/ri/4366/2/TCCG\%20-\%20BIBLIOTECONOMIA-JAQUELINE\%20MORAES\%20FERNANDES.PDF. Acesso em: 10 mar. 2021.

GIL, Antonio Carlos. Métodos e técnicas de pesquisa social. 6. ed. São Paulo: Atlas, 2008.

HARMERS, Josiane; BLANC, Michel. Bilinguality and Bilingualism. Cambridge: Cambridge University Press, 2000.

HEYE, J. Linguísticas - Panorama de Linguística Contemporânea: resumos das principais áreas de pesquisa. Notas de aulas, PUC-Rio, 2001.

KOTLER, Philip; ARMSTRONG, Gary. Princípios de marketing. 9. ed. São Paulo: Pearson Prentice Hall, 2003.

LUCKESI, Cipriano (org.). Ensaios de ludopedagogia. n.1. Salvador: UFBA/ FACED, 2000.

MACNAMARA, J. The Bilingual's linguistic performance. Journal of Social Issues, New York, v. 23, n. 2, p.58-77, 1967. DOI: https://doi. org/10.1111/j.1540-4560.1967.tb00576.x.

MARCELINO, Marcello. Bilinguismo no Brasil: significado e expectativas. Revista Intercâmbio, São Paulo, v. 19, p. 1-22, 2009. São Paulo: LAEL/ PUC-SP. ISSN 1806-275x.

MARTÍN MARTÍN, José Miguel. La adquisición de lalengua materna (L1) y elaprendizaje de una segunda lengua (L2)/lenguaextranjera (LE): procesos cognitivos y factores condicionantes. In: SÁNCHEZ LOBATO, Jesús; SANTOS 
GARGALLO, Isabel (orgs.). Vademécum para laformación de profesores: enseñarespañol como segunda lengua (L2)/lenguaextranjera (LE). Madrid: SGEL, 2004.

$M A X I M I A N O, A . C$. A. Introdução à administração. 6. ed. São Paulo: Atlas, 2004.

OLIVEIRA, Jorge Pacheco de. A competitividade nacional e a questão da língua. Ordem dos Economistas. 8 set. 2008. Disponível em: http://www. ordemeconomistas.pt/xportalv3/publicacoes/dossier.xvw?a-competitividade-nacional-e-a-questão-da-língua\&p=86303. Acesso em: 25 jan. 2020.

OLIVEIRA, Vera Barros de. O que é educação física. São Paulo: Brasiliense, 1985.

SANTHIAGO, Nayna da Silva. Contribuições da contação de história no processo de ensino-aprendizagem com foco no ciclo de alfabetização. Pró-Discente: Caderno de Produção Acadêmico-Científica, Vitória-ES, v. 24, n. 1, p. 55-74, jan./jun. 2018. Disponível em: https://periodicos.ufes.br/prodiscente/ article/view/20410. Acesso em: 20 fev. 2021.

SANTOS, Santa Marli Pires dos. Brinquedoteca: o lúdico em diferentes contextos. 4. ed. São Paulo: Vozes, 1999.

SANTOS GARGALLO, Isabel. Lingüística aplicada a laenseñanza-aprendizajedelespañol como lenguaextranjera. 3. ed. Madrid: Arco Libros, 2010.

SCHÜTZ, Ricardo E. O inglês como língua internacional. English Made in Brazil. 1998. Última atualização, 2018. Disponível em: https://www.sk.com.br/sk-ingl.html. Acesso em: 10 jan. 2021.

SCHÜTZ, Ricardo E. Assimilação natural x estudo formal. 2002. Última atualização, 2018. Disponível em: http://www.sk.com.br/sk-laxll.html. Acesso em: 15 nov. de 2020 .

SEVERO, Lessandra S.; SILVA, Edinice M.Sistema stanislavski: o processo criativo nas organizações. Revista de Ciências da Administração, v. 8, n. 15, jan./jun. 2006. Disponível em: https://periodicos.ufsc.br/index.php/adm/ article/view/1182/921. Acesso em: 20 fev. 2021.

SIGUÁN, Miguel; MACKEY, William. Éducation et bilinguisme. Paris: UNESCO, Delachaux et Niestlé, 1986. 
STANISLÁVSKI, Constantin. Construção da personagem. Tradução: Pontes de Paula Lima (da tradução norte-americana). Rio de Janeiro: Civilização Brasileira. 1970.

STANISLÁVSKI, Constantin. Etica y disciplina: método de acciones físicas: propedéuticadelactor. Seleção e notas de Edgar Ceballos. México: Grupo Editorial Gaceta, 1994.

VILLARDI, R. Ensinando a gostar de ler: formando leitores para a vida inteira. Rio de Janeiro: Qualitymark, 2005. 